\title{
The Relationship between Cultural Norms and Food Security in the Karamoja Sub-Region of Uganda
}

\author{
Solomon Olum ${ }^{1}$, Ipolto Okello-Uma ${ }^{1}$, Gaston A. Tumuhimbise ${ }^{2}$, David Taylor ${ }^{3,4}$, Duncan Ongeng ${ }^{1, *}$ \\ ${ }^{1}$ Department of Food Science and Post Harvest Technology, Gulu University, P.O. Box 166, Gulu, Uganda \\ ${ }^{2}$ Department of Food Technology and Nutrition, Makerere University, P.O Box 7062, Kampala, Uganda \\ ${ }^{3}$ Department of Geography, National University of Singapore, 1 Arts Link, Kent Ridge, Singapore 117570 \\ ${ }^{4}$ School of Natural Sciences, Trinity College, University of Dublin, Dublin 2, Ireland \\ *Corresponding author: d.ongeng@gu.ac.ug
}

\begin{abstract}
Culture is a strong determinant of food security through its influence on what society considers acceptable for consumption. Karamoja sub-region is one of the most ethnically diverse parts of eastern Africa, and is associated with the highest levels of food insecurity in Uganda. However, there is a general lack of understanding on the extent to which ethnicity is a contributing factor to food insecurity. We examined the relationship between ethnicity and food security in relation to commonly practiced cultural norms among the Jie, Karamojong and Tepeth ethnic groups of Karamoja. Data from 273 randomly selected households across a range of cultural settings were obtained using structured questionnaires in the September-October (2015) period. Food security status was assessed using the Household Food Insecurity Access Scale (HFIAS), daily calorie intake and coping strategy index. The study also used focus group discussions to assess the implications for food security of common cultural practices. Results confirm the general observation that the sub-region is food insecure. There were also significant variations in food security across geographical location and ethnicity. Cultural restrictions, applied particularly to women and children, over the consumption of several nutritious foods from livestock were revealed. Consumption of raw milk and animal blood, potential sources of food-borne infections and thus of malnutrition, was found to be high in the sub-region and varied significantly across ethnicity. The findings provide a basis for interventions aimed at reducing food insecurity and averting cultural impediments to a more nutritious diet.
\end{abstract}

Keywords: culture, food security, ethnicity, coping strategy index, Karamoja

Cite This Article: Solomon Olum, Ipolto Okello-Uma, Gaston A. Tumuhimbise, David Taylor, and Duncan Ongeng, "The Relationship between Cultural Norms and Food Security in the Karamoja Sub-Region of Uganda." Journal of Food and Nutrition Research, vol. 5, no. 6 (2017): 427-435. doi: 10.12691/jfnr-5-6-10.

\section{Introduction}

The proportion of undernourished people in developing countries has been high and relatively constant for the last two decades, especially in rural communities [1]. At a global level, increasing food production has been seen as a main factor in ensuring food security [2]. Despite this emphasis, available data indicate that about one billion people lack sufficient food, while a further one billion are poorly nourished [3]. At a national level, the level of food insecurity in Uganda has been rising since 1990 [4]. However, more crises occur at regional and local levels. Karamoja sub-region in North Eastern Uganda is characterized by the lowest human development indicators in the country [5]. The sub-region is also the most food insecure part of Uganda, with $20 \%$ of households extremely food insecure and more than $38 \%$ moderately food insecure [6,7]. The highest incidence of hunger and malnutrition is reported in this part of the country.

Hunger and malnutrition are not, however, simply due to shortfalls in availability of food at acceptable levels, but generally occur as a result of a combination of factors, including food quality, utilization and access. Thus malnutrition can occur even when food is available, if that food is of the 'wrong' kind as perceived by a given society, ethnic group or culture, or is otherwise inaccessible [8]. Household food insecurity occurs when a sufficient quantity of food is not supplied through household production (unavailability of food), when people lack the resources to obtain food from outside the household (inaccessibility of food), or when available and accessible food is not used to ensure a balanced diet for household members (improper utilisation of food) [9]. Food and nutrition insecurity both chronic (e.g. due to declining soil fertility, land shortages, a focus on low diversity, food production for cash, highly seasonal food production etc.) and transitory (e.g. due to anomalous weather conditions, such as drought, crop disease etc.) - have important health and economic consequences for those affected. Moreover, food has important social and cultural functions, and is seen as essential to keeping families together and to the maintenance of functioning communities [10]. The social role of foods is seen to vary across cultures. Ma [11] observed that food can differentiate between one culture and another. For instance, different cultures have different 'special' diets reserved for particular occasions, such as festivals. 
Food security is also influenced by cultural factors/norms [12] through, for example, food taboos or food preparation techniques associated with particular groups. This is because food is often subjected to cultural and personal filters prior to being considered appropriate for consumption. The different indigenous ethnic groups in Uganda are to an extent defined by their preferences for traditional foods [13]. Thus different foods have particular meanings and symbolism attached to them that affect their consumption [14]. Ma [11] observed that sources of nutrients vary significantly across localities. For example, the consumption of grasshoppers, potentially a useful source of protein, is common among some ethnic and cultural groups residing in central and western Uganda, while the practice is rare in other parts and among other groups. The Baganda of central Uganda value plantains (matooke type) so much that it is considered the best and most commonly eaten food (ibid). Furthermore, the Maasai in eastern Africa add local herbs to their main foods such as meat, blood, soup and milk [15]. In addition, the diversity of cultures in the region also impacts significantly food production, distribution, and consumption [16]. These cultural attachments that brand things as food or non-food consequently affect food and nutrition security. Redmond et al. [17] reported significant variations in Calcium and Phosphorus levels in the bones across a number of ethnic groups. These differences were attributed to difference in lifestyle related factors which have a strong link to culture and ethnicity (ibid).

Although food shortages in Karamoja sub-region have been known to arise as a result of anomalous weather conditions, declining soil fertility and civil insecurity [18], [19], there is limited information on the relationship between cultural practices and food security. Specifically, little account is taken in the literature of the extent to which culture and ethnic diversity relates to food security in one of the most food insecure and ethnically diverse regions of eastern Africa. This despite the fact that, for some communities, food and nutrition security is greatly influenced by factors that influence the utilization of food at household level [20]. For example, the method of preparation of food varies to a great extent among different ethnic groups. In addition, social acceptability of certain foods has been seen to vary significantly across cultures [21]. This is particularly important in a culturally and ethnically diverse area such as the Karamoja sub-region. According to Powel [22], only about 2\% of Uganda's total population resides in Karamoja sub-region. This relatively small number of people is divided among several ethnic groups, with some ethnic groups so few in members and occupying such a small geographical area that they are considered minority tribes. Culture presents a challenge to government agencies and NGOs that are active in promoting food security enhancement strategies. For instance, what is accepted by one culture may be rejected in part or in totality by another culture. Given the strong spatial influence of culture on food intake and subsequently food security, information from other geographical contexts is unlikely to be directly applicable to Karamoja sub-region. The research that underpins this paper examined the relationship between ethnicity and cultural norms on food security and highlights areas for possible intervention and deserving of further study. This is particularly important, given that improving food security in Karamoja sub-region in the aftermath of more than three decades of insecurity and stunted development [5] has recently gained more attention from development practitioners.

\section{Materials and Methods}

\subsection{Study Area Description}

Karamoja sub-region is located in north eastern Uganda and covers a total land area of about 27,900 square Kilometers. It has a population of about 1.1 million people (approximately 48 persons per square kilometer). The sub-region is comprised of the seven administrative districts of Moroto, Nakapiripirit, Amudat, Napak, Kotido, Abim and Kaabong. (Figure 1) [23]. The current study focuses on three major ethnic groups of Jie, Karamojong and Tepeth. To ensure fair representation of ethnic communities in the study, the districts of Kotido and Moroto were purposely selected. Kotido was selected because of the representation there of the ethnic groups Jie, Dodoth, and Labwor, while Moroto was selected because of the predominance of the Karimojong (sub-divided into the Matheniko, Pian and Bokora) and the Pokot and Tepeth ethnic groups. The selection of the two districts was also based on their locations and environmental conditions: Moroto is found in south Karamoja and is climatically relatively dry, while Kotido district, in the north, is climatically generally wetter than the south $[23,24]$.

\subsection{Study Design and Sampling Framework}

Research that underpins this paper adopted a cross-sectional approach. Data collection involved implementing a multi-stage sampling method in the study districts to select participating households. First, two sub-counties were randomly identified from each district (Nadunget and Tapac in Moroto, and Nakapelimoru and Kacheri in Kotido), and then households in two parishes in each sub-county were sampled. Data were collected from 273 households systematically sampled from eight parishes. A matrix indicating the sub-counties and parishes where the study was undertaken is shown in Table 1.

Table 1. Sub-counties and parishes studied

\begin{tabular}{|c|c|c|c|c|c|c|c|}
\hline District & \multicolumn{3}{|c|}{ Moroto } & \multicolumn{2}{c}{ Kotido } \\
\hline Sub-county & \multicolumn{2}{|c|}{ Nadunget } & \multicolumn{2}{c|}{ Tapac } & \multicolumn{2}{c|}{ Nakapelimoru } \\
\hline Parish & Loputuk & Acherere & Tapac & Kodonyo & Potongor & Watakau & Losakucha \\
\hline
\end{tabular}




\section{KARAMOJA DISTRICTS AND STUDY AREAS}

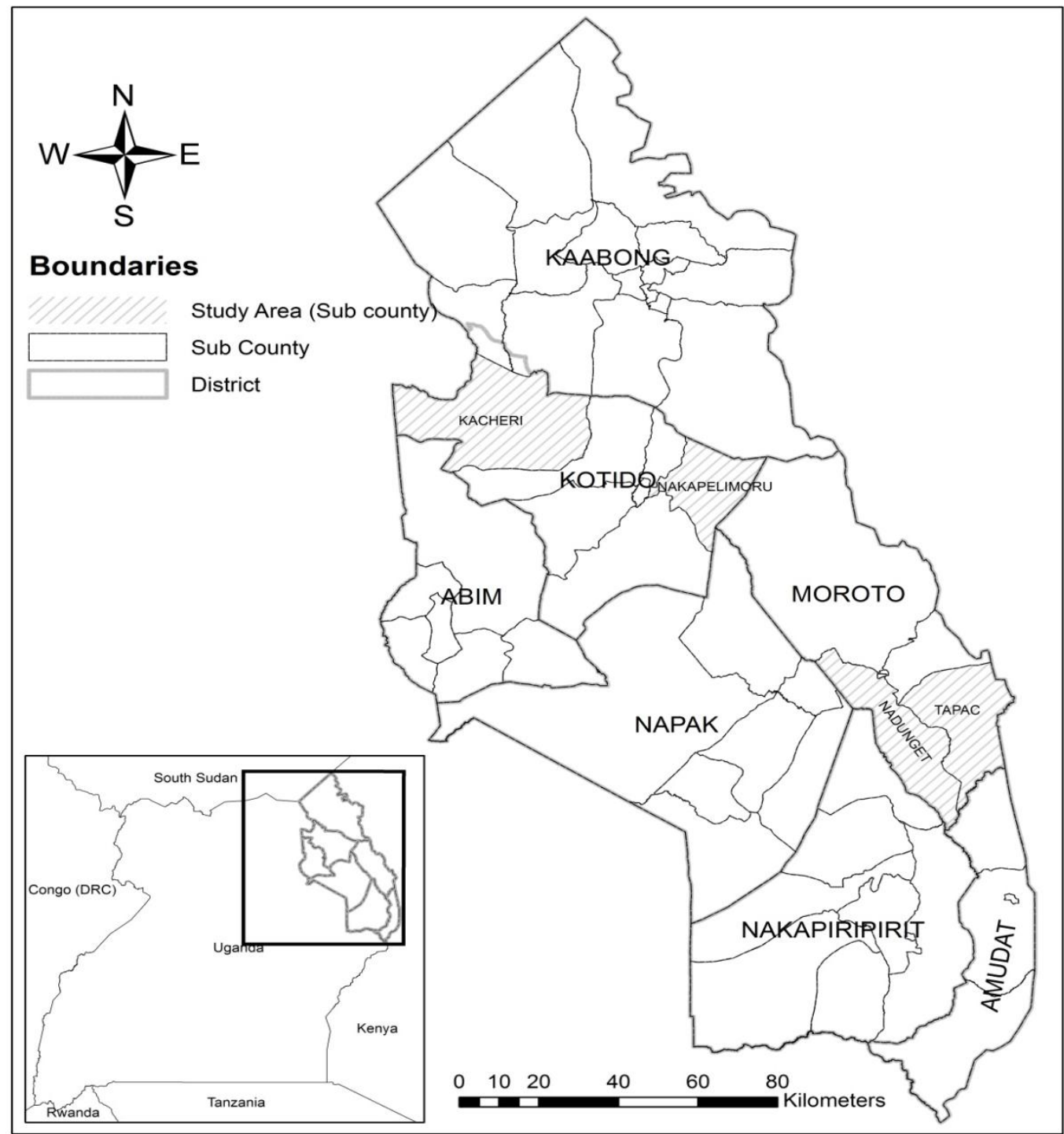

Figure 1. Map of Karamoja sub-region in northeastern Uganda showing the seven districts, including Moroto and Kotido, and the four sub-counties that are the focus of the current study

\subsection{Data Collection}

Data were collected by means of focus group discussions and household structured questionnaires. Focus group discussions were conducted to establish cultural norms that impact food intake in the study area. Each focus group consisted of 8 members and was segregated by gender. The selection of focus group members was based on their knowledge of the area and cultural practices. Three focus group meetings were held in total in September 2015. The first two focus group meetings were held separately for males and females to ensure that cultural restrictions affecting food intake of different groups of people could be expressed more freely than might otherwise have been the case. However, the third focus group had a mix gender and was used as a basis for verifying information from the first two focus groups. The discussions were held in relatively neutral locations within the two purposely selected districts.

Household interviews were used to assess the level of food security using the Household Food Insecurity Access Scale indicator (HFIAS), the Calorie Intake and the
Coping Strategy Index (CSI). The calorie, and water intakes were assessed using a single pass 24 hour dietary recall administered to the household main caregiver while the CSI was calculated from a weighted list of coping strategies, developed and validated by focus group discussion and administered to the households.

The HFIAS measures the access components of household food security in the past 30 days (4 weeks) according to Coates et al. [21] and as modified by Kabunga et al. [25]. This tool was developed by the Food and Nutrition Technical Assistance (FANTA) initiative of USAID. It helps to differentiate between food secure and food insecure households in culturally complex settings [9], such as found in Karamoja sub-region. From the HFIAS tool, three categories (domains) of questions with their sub-domains related to food access by households were included in the household questionnaire, using guidelines from Kabunga et al. [25]. The first domain represented anxiety and uncertainty about household food supply, the second domain represented food quality, and the third domain represented food quantity intake related to food availability at household level. A total of nine questions 
were asked and the response categories to the questions depicted the frequency of occurrence of conditions being investigated, and were assigned weights ranging from 0-3 according to Coates et al. [21]. The food insecurity score for each household was computed by summing the individual scores. The HFIAS scores therefore range from 0 , when the answer to all the 9 questions was "never" (showing maximum food security), to 27 , when the answer to all the questions was "often" (maximum food insecurity).

\subsection{Data Analysis}

The study used various methods to analyze the relationship between variables, making use of SPSS for windows, version 20. Specifically, the study used the student's t-test, chi-square test of association and analysis of variance to test for difference in significance and association between household food security indicators and the socio-economic variables that reflect culture. Specifically, the food security indicators were compared against the ethnicity of the respondents.

\section{Results}

\subsection{Household Food Security Status}

Overall, households in the study were food insecure. For instance, the average household calorie intake was $1,144 \mathrm{kcal}$. This is less than half of the recommended daily calorie intake for a healthy lifestyle. Variations in the level of food insecurity were evident across the study area. Households in Moroto had a significantly higher HFIAS ( $\mathrm{p}=0.047)$, and Coping strategy index (CSI) $(\mathrm{p}=0.000)$ than households in Kotido district. A high HFIAS and CSI are related to high levels of food insecurity. On the other hand, households in Kotido district had a significantly higher average number of meals per day $(p=0.032)$, average water intake per day $(p=0.000)$ and average calorie intake $(\mathrm{p}=0.000)$ (Table 2). Similarly, number of meals per day, daily water intake and calorie intake show the level of food intake and security for a given household. The results reveal that Moroto district is relatively more food insecure than Kotido district.

Consumption of raw milk and raw animal blood is a common practice in Karamoja sub-region. Overall, about $20 \%$ of the households reported consuming raw milk within the last 24 hours prior to the study. However, relatively more households $(26 \%)$ in Kotido reported consuming milk in the same period, compared with $9 \%$ in Moroto (Table 3). There were also more respondents in Moroto who had never consumed raw milk as compared to those in Kotido. Over $23 \%$ of the respondents consumed raw milk more than once a day. However, there were relatively more households in Kotido who reported consuming raw milk more than once a day. With respect to raw animal blood, $46 \%$ reportedly never consumed raw blood, while less than $5 \%$ of households consumed raw blood at least once a day. However, up to about a third of the households consumed raw animal blood at least once a month. There were significant variations in consumption of raw milk across districts.

Table 2. Household food security status

\begin{tabular}{|c|c|c|c|c|c|}
\hline \multirow{2}{*}{ Household Food Security Measure } & \multicolumn{4}{|c|}{ Mean (Standard error) } & \multirow{2}{*}{ p-value } \\
\hline & Overall $(n=273)$ & Moroto district $(\mathrm{n}=133)$ & Kotido district (n=140) & Mean Difference & \\
\hline HFIAS & $14.93(0.26)$ & $15.37(0.37)$ & $14.51(0.35)$ & $0.85(0.51)$ & 0.047 \\
\hline Average number of meals per day & $2.21(0.03)$ & $2.16(0.03)$ & $2.26(0.04)$ & $-0.10(0.05)$ & 0.032 \\
\hline Water taken per day (liters) & $2.08(0.67)$ & $1.84(0.09)$ & $2.31(0.11)$ & $-0.47(0.14)$ & 0.000 \\
\hline Calorie Intake (Kcal) & $1144.43(48.09)$ & $807.36(45.31)$ & $1474.178(74.25)$ & $-666.82(87.43)$ & 0.000 \\
\hline CSI & $108.15(2.64)$ & $120.85(3.42)$ & $96.08(3.73)$ & $24.77(5.08)$ & 0.000 \\
\hline
\end{tabular}

Table 3. Rate of consumption of raw blood or raw milk across the study area

\begin{tabular}{|c|c|c|c|c|c|}
\hline \multirow{2}{*}{ Variable } & \multirow{2}{*}{ Response Category } & \multicolumn{3}{|c|}{ Percentage } & \multirow{2}{*}{$\begin{array}{c}\text { Chi-Square } \\
\text { (p-value) }\end{array}$} \\
\hline & & Moroto district $(n=133)$ & Kotido district $(n=140)$ & Overall $(n=273)$ & \\
\hline \multirow{7}{*}{$\begin{array}{l}\text { Frequency of } \\
\text { Consumption of Milk } \\
\text { and any milk products } \\
\text { in the household }\end{array}$} & Never & 18.05 & 8.57 & 13.19 & \multirow{7}{*}{$41.03(\mathbf{0 . 0 0 0})$} \\
\hline & Once a day & 18.80 & 11.43 & 15.02 & \\
\hline & More than once a day & 11.28 & 35.00 & 23.44 & \\
\hline & 1-3 times a week & 25.56 & 25.00 & 25.27 & \\
\hline & 4-6 times a week & 4.51 & 12.86 & 8.79 & \\
\hline & once a month & 11.28 & 5.71 & 8.42 & \\
\hline & 2-3 times a month & 10.53 & 1.43 & 5.86 & \\
\hline \multirow{2}{*}{$\begin{array}{l}\text { Consumption of raw } \\
\text { milk in the past } 24 \text { hours }\end{array}$} & Did not consume & 90.98 & 73.57 & 82.05 & \multirow{2}{*}{$14.03(0.000)$} \\
\hline & Consumed & 9.02 & 26.43 & 17.95 & \\
\hline \multirow{7}{*}{$\begin{array}{l}\text { Number of times animal } \\
\text { blood is consumed in the } \\
\text { household }\end{array}$} & Never & 54.14 & 38.57 & 46.15 & \multirow{7}{*}{$13.57(\mathbf{0 . 0 3 5})$} \\
\hline & Once a day & 5.26 & 2.14 & 3.66 & \\
\hline & More than once a day & 1.50 & 2.14 & 1.83 & \\
\hline & 1-3 times a week & 4.51 & 10.71 & 7.69 & \\
\hline & 4-6 times a week & 2.26 & 5.00 & 3.66 & \\
\hline & Once a month & 30.08 & 35.00 & 32.60 & \\
\hline & 2-3 times a month & 2.26 & 6.43 & 4.40 & \\
\hline
\end{tabular}




\subsection{Influence of Cultural Norms on Food and Nutrition Security}

A comparison of food security indicators with household ethnicity reveals significant variations in food security status for the three major ethnic groups of Jie, Karamojong and Tepeth in the Karamoja sub-region. Specifically, HFIAS did not vary significantly across the various ethnic groups. However, number of meals per day, daily water intake, calorie intake and CSI all varied significantly across ethnic groups. For instance, average number of meals per day was lowest among the Karamojong, and highest among the Tepeth, while daily water intake was lowest among the Tepeth, but highest among the Jie ethnic groups. On the other hand, the mean calorie intake was highest among the Jie but lowest among the Tepeth, while CSI was highest for the Karamojong and lowest for Jie (Table 4). Although all ethnic groups were food insecure, the Jie ethnic group was relatively more food secure than the Karimojong and Tepeth ethnic groups.

In addition, consumption of raw animal blood and raw milk was prevalent and varied across ethnic groups. Consumption of raw blood and milk is characteristic of most ethnic groups in Karamoja sub-region. Specifically, frequency of consumption of raw milk and any milk products varied significantly across the major ethnic groups of the sub-region. For instance, a relatively large proportion $(30 \%)$ of the Karamojong ethnic group reported never consuming milk as compared with less than $10 \%$ of the Jie and Tepeth ethnic groups. In addition, up to about $28 \%$ of the Jie ethnic members reported consuming milk or its products in the 24 hours prior to the study, while only about $2 \%$ and $17 \%$ of, respectively, the Karimojong and Tepeth ethnic groups had not consumed raw milk 24 hours prior to the study (Table 5).

Inherent traditions of an ethnic group may dictate what should and should not be eaten by certain members of the group. In Karamoja sub-region, there is still a strong attachment to cultural practices that inhibit certain members of the society from consuming certain foods. Often the foods prohibited are highly nutritious. For instance, pregnant women are prohibited from eating most of the organ meat. A number of reasons are attached to such prohibitions. Offal for instance is prohibited for women in general since it is perceived that "any pregnant woman who eats it will have a miscarriage" (Table 6). Scrutiny of the reasons for prohibiting such foods reveals most of the reasons lack scientific basis and/or cannot be proven scientifically. Such taboos have often developed over time to the extent that, according to focus group discussions, they are now accepted without question by members of the group to which they apply. For example, most women are aware of such prohibitions, follow them strictly and would pass on knowledge of the restrictions to their daughters. As a consequence, incidences of victims violating such practices are rarely heard of.

Table 4. Comparing Household food security status by ethnicity

\begin{tabular}{|c|c|c|c|c|c|c|c|c|c|c|}
\hline \multirow[t]{2}{*}{ Ethnic Group } & \multicolumn{2}{|c|}{ HFIAS } & \multicolumn{2}{|c|}{ Number of meals per day } & \multicolumn{2}{|c|}{ Daily Water Intake(litres) } & \multicolumn{2}{|c|}{ Calorie Intake } & \multicolumn{2}{|c|}{ CSI } \\
\hline & Mean & SD & Mean & SD & Mean & SD & Mean & SD & Mean & SD \\
\hline Jie & $14.46^{\mathrm{a}}$ & 4.26 & $2.24^{\mathrm{a}}$ & 0.47 & $2.35^{\mathrm{a}}$ & 1.25 & $1416.19^{\mathrm{a}}$ & 860.22 & $95.51^{\mathrm{a}}$ & 43.60 \\
\hline Karimojong & $15.68^{\mathrm{a}}$ & 5.10 & $2.06^{\mathrm{b}}$ & 0.24 & $2.05^{\mathrm{a}, \mathrm{b}}$ & 1.18 & $750.20^{\mathrm{b}}$ & 545.35 & $119.21^{\mathrm{b}, \mathrm{c}}$ & 46.30 \\
\hline Tepeth & $15.05^{\mathrm{a}}$ & 3.13 & $2.26^{\mathrm{a}}$ & 0.51 & $1.64^{\mathrm{b}}$ & 0.74 & $870.27^{\mathrm{b}}$ & 504.20 & $123.36^{\mathrm{c}}$ & 31.00 \\
\hline F-value & 1.85 & & 4.68 & & 8.51 & & 24.04 & & 12.64 & \\
\hline P-value & 0.160 & & 0.010 & & 0.000 & & 0.000 & & 0.000 & \\
\hline
\end{tabular}

Note: Means in the same column with different superscripts are significantly different at $95 \%$ confidence level.

Table 5. Comparing frequency of consumption of raw blood and milk across the ethnic groups

\begin{tabular}{|c|c|c|c|c|c|}
\hline \multirow{2}{*}{ Variable } & \multirow{2}{*}{ Response Category } & \multicolumn{3}{|c|}{ Percentage } & \multirow{2}{*}{$\begin{array}{c}\text { Chi-Square } \\
\text { (p-value) }\end{array}$} \\
\hline & & Jie $(n=127)$ & Karimojong $(n=66)$ & Tepeth $(n=66)$ & \\
\hline \multirow{7}{*}{$\begin{array}{l}\text { Frequency of Consumption } \\
\text { of Milk and any milk } \\
\text { products in the household }\end{array}$} & Never & 7.87 & 30.30 & 6.06 & \multirow{7}{*}{$92.87(\mathbf{0 . 0 0 0})$} \\
\hline & Once a day & 11.02 & 4.55 & 33.33 & \\
\hline & More than once a day & 35.43 & 6.06 & 16.67 & \\
\hline & 1-3 times a week & 24.41 & 19.70 & 30.30 & \\
\hline & 4-6 times a week & 14.17 & 4.55 & 4.55 & \\
\hline & once a month & 5.51 & 18.18 & 4.55 & \\
\hline & 2-3 times a month & 1.57 & 16.67 & 4.55 & \\
\hline \multirow{2}{*}{$\begin{array}{l}\text { Consumption of raw milk } \\
\text { in the past } 24 \text { hours }\end{array}$} & Did not consume & 72.44 & 98.48 & 83.33 & \multirow{2}{*}{$19.96(\mathbf{0 . 0 0 0})$} \\
\hline & Consumed & 27.56 & 1.52 & 16.67 & \\
\hline \multirow{7}{*}{$\begin{array}{l}\text { Number of times animal } \\
\text { blood is consumed in the } \\
\text { household }\end{array}$} & Never & 38.58 & 57.58 & 50.00 & \multirow{7}{*}{$22.53(\mathbf{0 . 0 3 2})$} \\
\hline & Once a day & 1.57 & 1.52 & 9.09 & \\
\hline & More than once a day & 2.36 & 1.52 & 1.52 & \\
\hline & 1-3 times a week & 10.24 & 1.52 & 7.58 & \\
\hline & 4-6 times a week & 5.51 & 1.52 & 3.03 & \\
\hline & Once a month & 34.65 & 33.33 & 27.27 & \\
\hline & 2-3 times a month & 7.09 & 3.03 & 1.52 & \\
\hline
\end{tabular}


Table 6. Foods prohibited by culture for different groups of people in Karamoja sub-region

\begin{tabular}{|l|l|}
\hline English name of the food item (local name) & Reason (s) for prohibiting \\
\hline (a) Foods prohibited for consumption by women generally \\
\hline offals/animal intestine (Ngamolteng) & $\begin{array}{l}\text { Prohibited for married women because it is believed that they were spoilt by the first women who } \\
\text { ate them. }\end{array}$ \\
\hline Wild dodo: Amaranths spp (Ekiliton) & Affects their health status and it is believed that it makes somebody run mad \\
\hline Testis of animal (Nyito) & Young women will not reproduce if they consume this food \\
\hline Water from same source & $\begin{array}{l}\text { Girls of the same family who are married in one area do not share water from the same source } \\
\text { unless a ritual is performed or they die }\end{array}$ \\
\hline (b) Foods prohibited for pregnant women & A pregnant woman who eats them will get miscarriage \\
\hline Offals/animal intestine (Ngamolteng) & $\begin{array}{l}\text { The woman will fail to deliver but when they deliver the baby will defecate in the house always } \\
\text { or her other child will die }\end{array}$ \\
\hline Liver (Emany) & The woman will continue bleeding/over bleed after delivery \\
\hline Pancreas (Ecid) & When a woman delivers, the placenta will fail to come out \\
\hline Animal ribs (Ngamarang) & The pregnant women will miscarry or fail to deliver normally \\
\hline Aborted/ abnormally delivered calf (Ethecona) & The child will have regular bad mucus in the nose \\
\hline Brain of animals (Ngadam) & If a child eats it, his/her uncle will die \\
\hline (c) Foods prohibited for children & The child will not have good luck in most things \\
\hline Spinal cord/Vertebrae bone (Aka pul) & It limits harvest of foods by households \\
\hline Chicken which lack feather on the neck (Lokulas) & It is meant for young shepherd \\
\hline Insect/worm(Ekurit/Ekutelek) & \\
\hline (d) Foods prohibited for elders &
\end{tabular}

\section{Discussion}

In highlighting that populations in the study area of Karamoja sub-region are highly food insecure, the results of the current research are in agreement with those of earlier studies. According to World Food Programme, at least $42 \%$ of households in Karamoja are food insecure. The food insecurity levels however vary significantly across households. For instance, WFP [7] reported high variations of food insecurity in the sub-region with some sub-counties posting levels of the incidence of food insecurity as high as $70 \%$. Consumption of culturally significant foods was more prevalent in Kotido than in Moroto. For example, consumption of milk and blood is of cultural significance in Karamoja sub-region. Raw animal blood is usually mixed with untreated milk from their livestock. The results for frequency of consumption of raw milk and blood are concurrent with the food security status of the households; households in Moroto were relatively more food insecure than those in Kotido.

The results show that food security status in the most food insecure region of Uganda also varies significantly across ethnic groups. For instance, the Jie are relatively more food secure than the Karimojong and the Tepeth ethnic groups. The Jie were mostly found in Kotido, while the Karimojong and the Tepeth ethnic groups are more prominent in Moroto. Households in Kotido generally relied upon more nutritious foods than households in Moroto. Moreover, .region. This is in line with earlier findings. For instance, Agada and Igbokwe [26] reported that cultural differences across the three ethnic groups in their study had a strong influence on number of meals per day, food choices, preference of different foods, and agricultural production - and hence food security at the household level. Beckline and Kato [27] reported that culture, through its influence on food habits, was a strong determinant of food security in Buea district of Cameroon. Culture influences food security through a number of practices. However, food taboos are seen as major determinants of food security attributed to culture $[14,28]$.

Meyer-Rochow [28] observed that food taboos originate mainly due to cultural or religious reasons. Cultural or traditional norms inevitably affect food and nutritional security of households and communities. This is because foods need to be culturally acceptable in order to be readily consumed [29]. Results from the current research suggest that women and children suffer cultural restrictions on what they eat more than any other group in Karamoja sub-region. Furthermore the potential nutritional security and health implications of cultural restrictions on food consumption appear to be unappreciated by the wider community, at least according to the focus group discussions. Most of the restricted foods, including animal organs such as liver and pancreas, are highly nutritious, and limiting their consumption to older males places further pressure on nutritional security of females, children and adolescent males. For most cultures with food taboos or inhibitions, women and children are generally the most affected. Cultural taboos regarding particular food items are also likely to contribute to the already reported poor nutritional status of women and children in Karamoja sub-region [6]. Perez and Garcia [14] demonstrated that certain food taboos practiced by the Fulla of The Gambia contributed significantly to protein-energy malnutrition in Children and lactating women.

Hoddinott [30] noted that social norms regarding foods and who should consume them, and different levels of understanding of what foods to consume and in what quantities in order to ensure a well-balanced diet, are very 
likely to affect nutritional status. Moreover, malnourished women are likely to produce children whose nutritional statuses are also compromised [31], leading to a cyclic problem of malnutrition, as the malnourished children are equally likely to produce children of poor nutritional status [32]. Brown [31] elaborated the importance of maternal nutrition both before conception and during pregnancy. The author pointed out that sometimes conception occurs under conditions of poor nutrition or health, increasing the likelihood that fetal growth and development, and health of the mother during pregnancy will be compromised. Nutrition in the first 1000 days of human life is known to be a critical factor influencing growth and development of a child and the level of contribution that an individual can make to economic development over their lifetime $[33,34]$.

According to Meyer-Rochow [28], there are food taboos that have a scientific basis, such as those associated with allergic reactions. However, most taboos have no scientific basis and instead are based on beliefs attributed to a specific culture (ibid). Often such scientifically baseless taboos discriminate against particular members of society such women and the young [35,36]. Some food taboos are put in place to maintain societal cohesion [28]. According to Ma [11], food is also important in establishing and maintaining relationships between members of the society.

In order to increase food and nutritional security of the households as a whole, strategies should consider food taboos that discriminate against certain members of society. Nutrition education has been shown to improve nutritional behaviour and practices $[37,38]$. This is against the background that some of the taboos have persisted due to lack of an understanding of the nutritional benefits of prohibited foods. Examining whether education can be used to counteract cultural norms that negatively affect nutritional security of women and children in Karamoja sub-region is a potential area of future study and intervention.

A clear link exists between nutrition and overall health, and between certain components of a diet and debilitating disease [31]. The consumption of raw milk and blood was found to be commonplace in this study. Indeed, a key informant alluded that all the communities in Karamoja sub-region consume raw milk and raw blood. The informant added that the two foods are mixed together (mixture locally known as asarakan in Kotido district) and consumed raw. Although a useful source of nutrition, the consumption of raw milk and blood places the consumers at high risks of contraction of food borne infections [39], in addition to relatively minor illnesses such as diarrhea (which can quickly become serious ailments if the sufferer is already malnourished). For example, Heuvelink et al. [40] report that two cases of outbreak of Campylobacteriosis in the Netherlands were associated with the consumption of raw milk. Lucey [41] observed that up to a third of raw milk samples had (human) pathogens even in cases where the milk is from clinically healthy animals.

Meat, milk and dairy products are key sources of zoonoses of bovine origin [42] when not properly processed. For instance, the consumption of raw animal products carries with it a high risk of brucellosis and bovine tuberculosis infections $[43,44]$. Clearly, treatment (pasteurization) of milk is an important step in preventing the occurrence of food borne infections. According to Lucey [41] the risk of acquiring zoonotic diseases from raw milk was one of the major reasons for the introduction of milk pasteurization procedures. The occurrence of food-related infectious diseases could in turn impact agricultural productivity of affected households by reducing, directly and/or indirectly, the availability of farm labour. Findings presented in this paper provide a strong argument for tailoring health education so that it covers both the non-communicable and communicable aspects of food security-related poor health among households in Karamoja sub-region.

\section{Conclusions}

Food insecurity in the Karamoja sub-region varies significantly across geographic location and across ethnic groups. Ethnicity directly influences cultural practices which dictate those foods that can be utilized by specific groups of the society and those that cannot. Cultural norms also placed restrictions on the consumption of nutritious foods, with women, children and adolescent males particularly affected. Specifically, the restrictions target organ meat and some vegetables that are highly nutritious. The level of consumption of raw milk and raw blood, sources of potentially highly harmful food borne infections, also vary significantly among the study communities. Findings presented in this paper provide a basis for more effective, culturally-sensitive interventions targeting resources aimed at alleviating problems relating to food insecurity in Karamoja sub-region than is currently the case. For instance, through specifically designed programs, food cultures that impose restrictions on certain members of society can be systematically discouraged to ensure equal opportunities for all in the consumption of nutritious foods. One of the interventions that would tackle both the challenge of nutrition insecurity as a result of food taboos, and the risk of communicable and noncommunicable diseases, is nutrition education. Education on nutrition in general and on the nutritional benefits (or dis-benefits) of traditional practices in particular would benefit food security in Karamoja sub-region. It is also likely to be of relevance, and benefit, more widely in eastern Africa and in other relatively undeveloped parts of the sub-Saharan Africa.

\section{Statement of Competing Interests}

The authors declare that they have no conflict of interest.

\section{Acknowledgements}

The study was supported by Irish Aid through NOURISH (Nutrition and Treatment Outcome: Development of a Ugandan - Irish HIV/Nutrition Research Cluster) project (Trinity College Dublin and Gulu University partnership). Prof. Martina Hennessy, Sarah Glavey 
(Trinity College Dublin), Dr. Basil Mugonola and Daniel Micheal Okello (Gulu University) and Dr. Daniel Aleper are acknowledged for their comments at all levels of the research work that helped improve the overall write up. We would like to thank Gustavio Okwir (Department of Biosystems Engineering, Gulu University) for helping in producing map of the study area.

\section{References}

[1] Cordero-Ahiman, O. V., Santellano-Estrada, E., and Garrido, A., "Dietary Diversity in Rural Households: The Case of Indigenous Communities in Sierra Tarahumara, Mexico," Journal of Food and Nutrition Research, 5 (2). 86-94. 2017.

[2] Godfray, H. C. J., Beddington, J. R., Crute, I. R., Haddad, L., Lawrence, D., Muir, J. F., et al., "Food security: the challenge of feeding 9 billion people," Science, 327. 812-818. 2010.

[3] Misselhorn, A., Aggarwal, P., Ericksen, P., Gregory, P., HornPhathanothai, L., Ingram, J., et al., "A vision for attaining food security," Current opinion in environmental sustainability,. 4. 7-17. 2012

[4] FAO., IFAD., and WFP. "The State of Food Insecurity in the World: Meeting the 2015 international hunger targets - taking stock of uneven progress. ," ed. Rome: The Food and Agriculture Organization of the United Nations, 2015.

[5] O'Keefe, M., "Chronic Crises in the Arc of Insecurity: a case study of Karamoja," Third World Quarterly, vol. 31, pp. 1271-1295, 2010.

[6] Shively, G., and Hao, J., "A review of agriculture, food security and human nutrition issues in Uganda," Department of Agricultural Economics, Purdue University, 2012.

[7] WFP., "Food Security and Nutritional Assessment: Karamoja Region Uganda.," ed. Kampala,: World Food Programme, 2015.

[8] Jehn, M., and Brewis, A., "Paradoxical malnutrition in motherchild pairs: untangling the phenomenon of over-and undernutrition in underdeveloped economies," Economics \& Human Biology, 7. 28-35. 2009.

[9] Ndirangu, M., Sachs, S. E., Palm, C., and Deckelbaum, R. J., "HIV affected households in Western Kenya experience greater food insecurity," Food policy, 42. 11-17. 2013.

[10] Noack, A.-L., and Pouw, N. R., "A blind spot in food and nutrition security: where culture and social change shape the local food plate," Agriculture and human values, 32 (2). 169-182. 2015.

[11] Ma, G., "Food, eating behavior, and culture in Chinese society," Journal of Ethnic Foods, 2(4). 195-199. 2015.

[12] Lambden, J., Receveur, O., and Kuhnlein, H. V., "Traditional food attributes must be included in studies of food security in the Canadian Arctic," International Journal of Circumpolar Health, 66 (4). 308-319. 2007.

[13] Amone, C., "We are strong because of our millet bread: staple foods and the growth of ethnic identities in Uganda.," Journal of the Humanities and Social Sciences, 18. 159-172. 2014.

[14] Pérez, G. M., and García, A. P., "Nutritional Taboos among the Fullas in Upper River Region, The Gambia." Journal of Anthropology, 2013.

[15] Saitoti, A., People and Their Food Cultures: The Maasai. Nairobi:: East African Publishing House., 2010.

[16] Lyana, A. Z., and Manimbulu, N., "Culture and Food Habits in Tanzania and Democratic Republic of Congo," Journal of Human Ecology, 48. 9-21. 2014.

[17] Redmond, J., Jarjou, L. M. A., and Zhou B., Prentice, A., and Schoenmakers, I., "Ethnic differences in calcium, phosphate and bone metabolism" Proceedings of the Nutrition Society, 73. 340-351. 2014

[18] Nkonya, E., Kaizzi, C., and Pender, J., "Determinants of nutrient balances in a maize farming system in eastern Uganda," Agricultural systems, 85. 155-182. 2005.

[19] Nkonya, E., Pender, J., Kaizzi, C., Edward, K., and Mugarura, S., Policy Options for Increasing Crop Productivity and Reducing Soil Nutrient Depletion and Poverty in Uganda: Intl Food Policy Res Inst, 2005.

[20] Mello, J. A., Gans,K. M., Risica P. M., Kirtania, U., Strolla, L. O., and Fournier, L., "How is food insecurity associated with dietary behaviors? An analysis with low-income, ethnically diverse participants in a nutrition intervention study," Journal of the American Dietetic Association, 110. 1906-1911. 2010.

[21] Coates, J., Frongillo, E. A., Rogers, B. L., Webb, P., Wilde, P. E., and Houser, R., "Commonalities in the experience of household food insecurity across cultures: what are measures missing?," The Journal of nutrition, 136. 1438S-1448S. 2006.

[22] Powel, J., "Karamoja: A Literature Review.," ed. Kampala: : SaferWorld, 2010

[23] Egeru, A., Wasonga, O., Mburu, J., Yazan, E., Majaliwa, M. G., MacOpiyo, L., et al., "Drivers of forage availability: An integration of remote sensing and traditional ecological knowledge in Karamoja sub-region, Uganda," Pastoralism, 5. 19. 2015.

[24] Quam, M. D., "Creating Peace in an Armed Society: Karamoja, Uganda, 1996.," African Studies Quarterly, 1. 1997.

[25] Kabunga, N. S., Dubois, T., and Qaim, M., "Impact of tissue culture banana technology on farm household income and food security in Kenya," Food Policy, 45. 25-34. 2014.

[26] Agada, M., and Igbokwe, E., "Influence of Food Culture and Practices on Household Food Security in North Central Nigeria," Journal of Food Security, 4. 36-41. 2016.

[27] Beckline, M., and Kato, M. S., "Assessing the Impact of Consumer Behaviour on Food Security in South West Cameroon," Journal of Food Security, 2. 87-91. 2014.

[28] Meyer-Rochow, V. B., "Food taboos: their origins and purposes," Journal of Ethnobiology and Ethnomedicine, 5. 18, 2009.

[29] Ruel, M. T., Garrett, J. L., Morris, S. S., Maxwell, D., Oshaung, A., Engel, P., et al., "Urban challenges to food and nutrition security: A review of food security, health and caregiving in the cities.," FCND Discussion paper No.51.IFPRI., 1998.

[30] Hoddinott, J., "Agriculture, health, and nutrition: Toward conceptualizing the linkages. Reshaping Agriculture for Nutrition and Health," ed. Washington, DC.: International Food Policy Research Institute, 2012.

[31] Brown, J. E., Nutrition Through The Life Cycle. Nutrition Basics. , 4 ed.: Wadsworth: Cengage Learning 2011.

[32] Bouis, H., and Hunt, J., "Linking food and nutrition security: past lessons and future opportunities," Asian Development Review, 17. 168-213. 1999.

[33] Poindexter, B. B., and Langer, J. C., "Early provision of parenteral amino acids in extremely low birth weight infant: Relation to growth and neurodevelopment outcome. ," The journal of Pediatrics, 148 (3). 300-305. 2006.

[34] Stephens, B. E., Walden, R. V., Gargus, R. A., Tucker, R., Mckinley, L., Mance, M., et al., "First-Week Protein and Energy Intakes are associated with 18-Month Development Outcomes in Extremely Low Birth Weight Infants. " Pediatrics, 123(5). 1337-1343. 2009.

[35] Asi, L. N., and Teri, D. T., "Influence of food taboos on nutritional patterns in rural communities in Cameroon," International Review of Social Research, 6. 35-39. 2016.

[36] Mengesha, A. D., and Ayele, T. T., "The Impact of Culture on the Nutritional Status of Children and Mothers Durrinng Recurring Food Insecurity: The Case of Boreicha Woreda (SNNPRS)," American Journal of Educational Research, 3 (7). 849-867. 2015.

[37] Hotz, C., and Gibson, R., "Participatory nutrition education and adoption of new feeding practices are associated with improved adequacy of complementary diets among rural Malawian children: a pilot study," European journal of clinical nutrition, 59. 226-237. 2005.

[38] Guldan, G. S., Fan, H.-C., Ma, X., Ni, Z.-Z., Xiang, X., and Tang, M.-Z., "Culturally appropriate nutrition education improves infant feeding and growth in rural Sichuan, China," The Journal of nutrition, 130 (5). 1204-1211. 2000.

[39] Jayarao, B. M., Donaldson, S. C., Straley, B. A., Sawant, A. A., Hegde, N. V., and Brown, J., "A survey of foodborne pathogens in bulk tank milk and raw milk consumption among farm families in Pennsylvania," Journal of dairy science, 89 (7). 2451-2458. 2006.

[40] Heuvelink, A. E., van Heerwaarden, C., Zwartkruis-Nahuis, A., Tilburg, J. J., Bos, M. H., Heilmann, F. G., et al., "Two outbreaks of campylobacteriosis associated with the consumption of raw cows' milk," International journal of food microbiology, 134. 70-74. 2009.

[41] Lucey, J. A., "Raw milk consumption: risks and benefits," Nutrition Today, 50 (4). 189. 2015.

[42] Cavirani, S., "Cattle industry and zoonotic risk," Veterinary research communications, 32. 19-24. 2008. 
[43] Etter, E., Donado, P., Jori, F., Caron, A., Goutard, F., and Roger, F., "Risk Analysis and Bovine Tuberculosis, a Re-emerging Zoonosis," Annals of the New York Academy of Sciences, 1081. 61-73. 2006.
[44] Amenu, K., Thys, E., Regassa, A., and Marcotty, T., "Brucellosis and tuberculosis in Arsi-Negele District, Ethiopia, Prevalence in ruminants and people's behaviour towards zoonoses," Tropicultura, 28 (4). 205-210. 2010. 